\title{
Ötzi, the Iceman and his Leather Clothes
}

\author{
Alois G. Püntener ${ }^{\mathrm{a}}$ and Serge Moss*
}

\begin{abstract}
Over 5000 years ago, a man climbed up to the icy heights of the glacier in South Tyrol, Italy and died. He was found by accident in 1991, with his clothes and equipment, mummified and frozen: an archaeological sensation and a unique snapshot of a Copper Age man. For several years highly specialised research teams have examined the mummy and all accompanying items. This paper describes how fur and leather clothes of the iceman could have been tanned. Details of the analytical tests undertaken on the 5000 year old leather samples and what they revealed are presented.
\end{abstract}

Keywords: Ancient tanning method · Iceman · Infrared spectroscopy $\cdot$ Neolithic leather clothing

Socrates says that a state is made up of four sorts of people who are absolutely necessary; these are a weaver, a husbandman, a shoemaker, and a builder.

Aristotle, Politics, Book 4, IV

\section{Introduction}

On Thursday, September 19, 1991 at $1.30 \mathrm{pm}$, a married couple found a dead body in the Alps on the icy heights of the Schnalstal glacier, $3210 \mathrm{~m}$ above sea level and in the frontier area of Tyrol between Italy and Austria. ${ }^{[1,2]}$

The Austrian police were informed. At first glance, the police officer found strange clothes and pieces of equipment and concluded that the accident must have happened 100 years ago. He also believed that the body had a head injury. Did a crime happen 100 years ago? The federal prosecutor assigned the examining magistrate to initiate a medico-legal investigation. But nobody was in a hurry. The accident was assumed to be an old affair, which had happened years ago, and was almost forgotten. The retrieval of the body by helicopter was not considered since this was restricted

\footnotetext{
${ }^{*}$ Correspondence: S. Moss

Novartis Pharma AG

Forum 1

Novartis Campus

$\mathrm{CH}-4056$ Basel

Tel.: +41613246212

E-mail: serge.moss@novartis.com

aVESLIC Verein Schweizerischer Lederindustrie-

Chemiker und -Techniker

c/o Dr. A.G. Püntener

Postfach 505

$\mathrm{CH}-4016$ Basel

E-mail: veslic@hotmail.ch
}

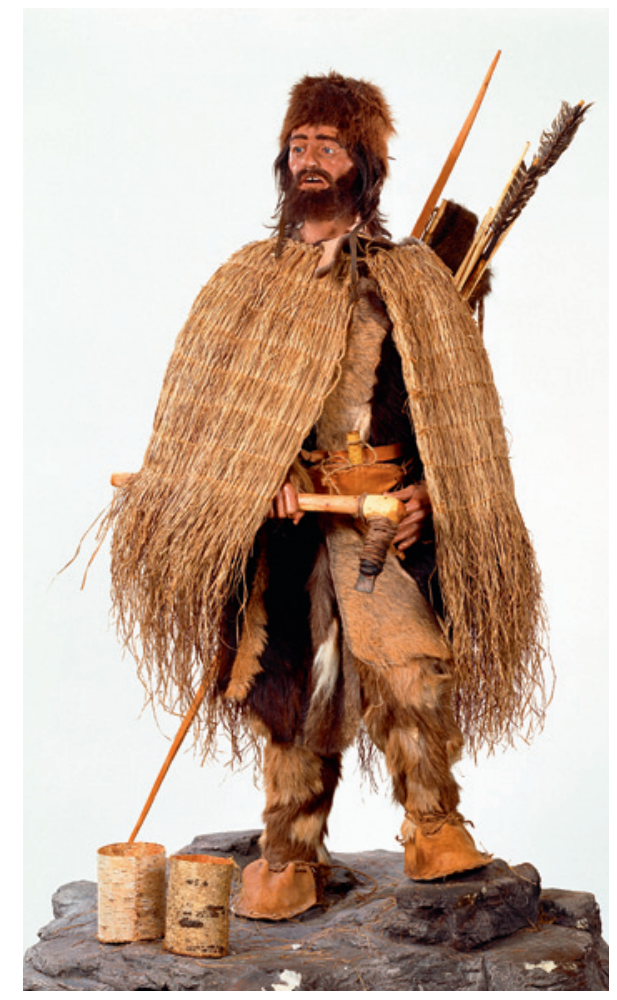

Fig. 1. Ötzi the Iceman. Source and copyright of the picture: South Tyrol Museum of Archaeology.

to more urgent events such as traffic and mountain accidents, especially because the weekend was approaching.

However, the story attracted the media's attention. They speculated that the body was a soldier from the middle ages: a mercenary coming home after a warlike event in Italy. First investigations of the mummy, its clothes and equipment revealed that the Iceman mummy was a male inhabitant of the Alps. A carbon-14 analysis indicated that he was much older than so far assumed (Fig. 1). He lived during the Copper Age (Neolithic), over 5000 years ago. It was speculated that he could have been a soldier, hunter or herdsman. During the first inspection and rescue work his skull was determined to have been broken. Later, an arrowhead was discovered in his body. He was mortally wounded upon escaping over the mountains. He was moving from today's Italian lowland in the direction of the Ötztal valley, now Austria. The name 'Iceman' or his nickname 'Ötzi' was created.

\section{Research on the Iceman}

For the first time in the history of medicine and archaeology, anatomical studies could be performed on a mummy clearly dated to the 4th millennium BC. ${ }^{[3]}$ With the exception of the damaged left hip region, the body was practically intact. It has been on exhibit since March 1998 at the South Tyrol Museum of Archaeology in Bolzano, Italy. For several years highly specialised research teams examined the mummy and all accompanying items. The most impressive item was the copper axe, certainly used as a tool and a weapon.

Not much was known about clothing in the Neolithic time. Spindle whorls and loom weights have been found as well as some textile fragments of flax and other vegetable fibres. According to archaeological excavations weaving must have been known in the region at that time. Ötzi allows us a view of the general appearance of an alpine inhabitant more than 5000 years ago. The clothing found had been conserved in a surprisingly good condition.

The clothing is composed of a fur cap, a hide coat, a grass cloak, leggings, a belt, a loincloth and a pair of shoes. It is remarkable that no woven materials were used, only tanned leather and a grass coat. The fur clothing has a black/brown coloured stripe design. ${ }^{[3]}$ The cap, the coat and the leggings are composed of many cut pieces sewn together. The stitching threads are mainly made of animal sinews and only in part of plants, primarily grasses and to a lesser extent bast. 
Our interest was the fur and leather clothing. The museum curators had washed every sample with distilled water containing 2\% borax and boric acid and 20\% polyethylenglycol as well as with a fatty emulsion. This treatment could have been somewhat inconvenient as it could interfere with the analytical investigation of the conservation process. Fortunately, we did not detect any interference from this treatment and we therefore believe that it did not negatively impact our investigation.

We have to consider that skin material is normally subject to rapid decomposition after the animal is killed. The first reaction takes place on the epidermis. A fast separation of the hair occurs. Therefore, for the fur and leather industry it is of great importance that the raw hide is properly treated immediately after slaughter. The best method to protect hide from deterioration is to remove water, either by drying or salting. Raw hide is still treated in this manner worldwide today before being tanned. However, these methods alone cannot withstand daily usage under adverse alpine weather conditions.

The fur and leather items of the iceman were almost completely intact. That indicated quite clearly that his clothes had been tanned, keeping them very stable under the conditions prevailing in the glacier area. This effective conservation allowed us to perform analytical tests, finally enabling the investigation and discovery of the little known tanning method of our alpine ancestors, which is of great historic interest.

The fur cape was made of a bear hide, not an easy animal to hunt. The clothing fur was first identified as mainly chamois, ${ }^{[4]}$ a more common hunting animal, though rarely used today as the hairs are too stiff and readily break. The fur was kept in good condition. The clothing had been repaired reasonably skilfully on several occasions. The furs were obviously designed and used for a long lifetime.

The experience that chamois fur is rigid and fragile was also made by the Iceman. He wore apparently hairless treated skin, more like leather. The few remaining hairs and epidermis on the samples show that the hair had been worn off by extensive use. This may also have happened to his shoes. The inner shoe is composed of grass netting. The outer part is made of leather/fur. Therefore, the original material must have been fur (see light microscopy, Fig. 2).

Recently German researchers, analysing proteins present in the hairs of Ötzi's clothing with a hi-tech MS method and comparing them with those found in living animals, assigned samples from the coat and from the leggings to sheep and the upper leather of his moccasins to cattle. ${ }^{[5]}$ These results support the theory that Ötzi was a member of a more developed

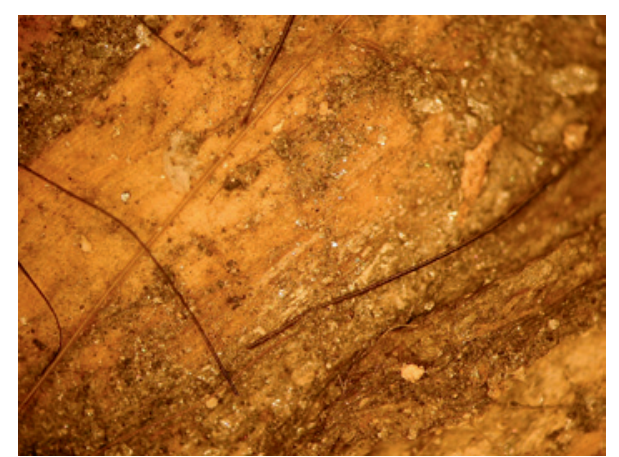

\subsection{Vegetable Tanning}

Vegetable tanning sources are woods, barks, leaves, fruits, roots or growths (gallnuts). The tanning active compounds are organic macromolecules with aromatic components. Vegetable tanning agents are usually sourced locally. At that time oak, birch, chestnut or spruce or barks could have been used as tanning agents.

The tanning effect of vegetable tans is based on polymeric phenol groups. An example is polymeric gallic acid as ellagic acid and their lactones in the form of gly-

Fig. 2. Surface of the hair (grain) site of the Ötzi leather ( $7 \times$ magnification).

society of farmers and ranchers rather than of a society of hunters.

Whatever kind of fur has been used, some tanning must have been carried out otherwise the material would have not been stable in the alpine climate. In the tanning trade one performs a fixation of tanning agents within the collagen matrix. The quality of the leather is improved with increasing degree of fixation, which is measured by the so-called shrinking temperature. The epidermis and the corium must be strongly connected to each other. Comparative shrinking temperatures according to the DIN 53336 method show $46-49{ }^{\circ} \mathrm{C}$ for untreated hide and $58-60{ }^{\circ} \mathrm{C}$ for the Iceman's furs. This is a clear indication that some tanning had been undertaken. In addition, before tanning the hypodermis (subcutus) must be removed. Studies showed that this had been done mechanically as scrape marks, probably from a flint stone, were found. What technique could have been used to tan the leather clothes of the Iceman?

\section{Possible Tanning Methods}

We can assume in principle four tanning procedures which could have been known or may have been practised at that time: metal tanning, fat tanning, smoke tanning or vegetable tanning. ${ }^{[6-9]}$

\subsection{Metal Tanning}

Metal salts like alum were known and used in ancient Egypt. The western desert of Egypt was a major source of alum substitutes in antiquity. These could also be found in the local Alpine area, commonly in caves. Today, potassium, simple aluminium chlorides and aluminium sulphate tanning [e.g. $\left.\mathrm{KAl}\left(\mathrm{SO}_{4}\right)_{2} \cdot 12 \mathrm{H}_{2} \mathrm{O}\right]$ are still used for leather gloves.

However, these substances should be highly basic or masked, otherwise the tanning could be easily washed out. Therefore, this tanning method may not be very suitable for the Alpine region, where rain and snowfall prevail. coside (Fig. 3).

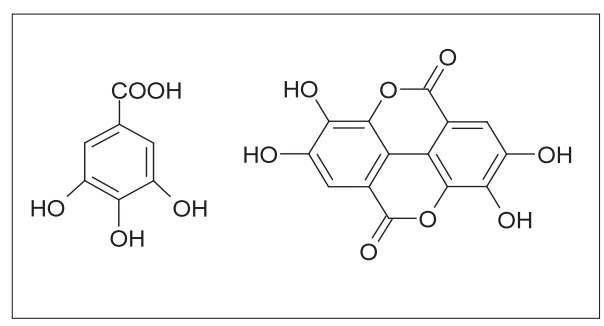

Fig. 3. Gallic acid and ellagic acid.

\subsection{Smoke Tanning}

One can also envisage the use of smoke, which has an antibacterial and conservation effect. In addition it also has a dehydration effect. Wood smoke components consist of a multitude of chemical compounds including small amounts of tanning agents like phenolic and formaldehyde derivatives. This method cannot be considered as mainstream tanning. However, smoke influences the smell of leather and fur depending on the selection of fire material. In our investigation we could not find any convincing indication for smoke tanning. Nevertheless, we have to assume that clothing almost certainly will have had intensive contact with smoke due to the in the Alps during Neolithic times. For instance, smoking meat for food preservation is an old and well known procedure.

\subsection{Fat Tanning}

The most obvious means for skin preparation was probably the use of fat. The observation that fat stuffing has the characteristic to make rough and hard materials soft must have been known. The fur must be soft for the sewn repairs as done by Ötzi. In addition, fat has some water-repellent effects. It is most likely that for tanning fat materials of slaughtered animals (booty) could have been used. The use of vegetable fat is very unlikely as it was and remains very difficult to collect.

The composition of animal fatty components varies. For land animals it consists of triglycerides, mainly of stearic, palmitic weather, housing and cooking conditions 
and a smaller amount unsaturated oleic acid. This is in contrast to fish oil which contains a higher amount of unsaturated fat. Saturated fatty components are incorporated physically into the hide and they show less tanning behaviour than chemical tanning.

The unsaturated bonds in fish oil break at approximately $45^{\circ} \mathrm{C}$. They create formaldehyde derivatives which lead to a real tanning bond with the hide. In tanning procedures in German it is called 'Sämischgerbung' and in English 'Chamois tannage'. We know this effect from our daily life, it is basically the same type of reaction which makes butter rancid. At present, 'Sämischgerbung' is still used for Tyrolean trousers made from the skin of red deer, chamois, reindeer and elks.

There are different application methods for fat stuffing. It can be performed at high temperatures, using eggs, brains or other emulsifiers, gypsum, highly colloidal clay or other powdery supporting materials.

\section{Analytical Findings}

\subsection{Search for Metals}

Atom absorption spectroscopy (AAS) was used to identify the presence of metals. Four different samples from the Iceman's leather were investigated and the hair (grain) and the flesh side analysed separately (Table 1 ). Vegetable tanned leather was taken as reference. The chemical elemental distribution on the Iceman's leather is very uneven. Aluminium and iron were found in high concentrations in all samples, beside intriguingly high amounts of elements such as calcium, magnesium and titanium. It is likely that many of these elements derive from a contamination by silicate impurities since silicon was also detected in high concentration. In fact, an analysis of individual sand grains taken from the Ötzi's leather samples resulted in similar concentrations of silicon, aluminium, iron, magnesium and titanium. Iron could also originate from dried blood as Ötzi was mortally wounded, but its presence could also be explained by some kind of tanning practice since natural pigments like iron ochre were used in ancient times, for example, to paint human bodies.

Such findings trigger the question whether all of the elements found in the Iceman's leather come exclusively from natural soil or, at least partly, arise from a tanning process. This question could not be answered unequivocally at this stage of the investigation. However, we consider metal tanning to be rather unlikely.

\subsection{Search for Vegetable Tanning}

To detect vegetable tanning agents several extractions with solvents and solvent mixtures like water/alcohol were performed and the extracts analysed by different analytical methods (IR, TLC) but the search was negative. Also decomposition (pyrolysis-gas chromatography/mass spectrometry, Py-GC/MS) of a very small fur sample showed no aromatic vegetable tanning components. ${ }^{[10]}$

\subsection{Search for Fat Tanning}

In order to search for fatty components the leather samples were analyzed by infrared (IR) spectroscopy. To this end the attenuated total reflectance (ATR) technique

Table 1. Result of AAS analysis.

$\begin{array}{lll}\text { Chemical Element } & \text { Reference Leather [\%] } & \text { Iceman Leather [\%] } \\ \mathrm{Si} & 0.02-0.07 & 1.5-5.0 \\ \mathrm{Al} & 0.02-0.04 & 1.0-3.0 \\ \mathrm{Fe} & 0.01 & 1.5-4.0 \\ \mathrm{~S} & 2.0 & 0.2-0.7 \\ \mathrm{Ca} & 0.1-0.2 & 0.1-1.0 \\ \mathrm{Na} & 0.2 & 0.7-1.0 \\ \mathrm{~K} & 0.1-0.2 & 0.1-0.7 \\ \mathrm{Mg} & 0.01-0.02 & 0.2-0.6 \\ \mathrm{P} & 0.03-0.1 & 0.06-0.3 \\ \mathrm{Cl} & 0.06-0.1 & 0.01-0.02 \\ \mathrm{Cr} & <0.01 & <0.01 \\ \mathrm{Ti} & <0.001 & 0.03-0.1 \\ \mathrm{Ba} & <0.001 & 0.005-0.03\end{array}$

was used first. This technique allows infrared spectra of samples to be measured which cannot be damaged and is widely used for the analysis of paper, textile, plastic or leather samples. No sample preparation is required. The sample is simply placed in contact with a special crystal and can be recovered after the measurement. For the analysis of large areas the frustrated multiple internal reflectance (FMIR) method was used whereas small areas could be targeted by using the ATR objective of an IR microscope with about 100 micron contact area. ATR microscopy has been also applied to the analysis of skin samples of mummified corpses, including that of the Iceman. ${ }^{[11,12]}$

For each piece of leather both the hair and the flesh side were investigated. Due to the large heterogeneity of the samples and also the presence of dirt and hair, considerable differences were occasionally observed between the spectra of the same sample, and even between spectra of the same side of the same piece of leather. However, most spectra resemble the spectrum shown in Fig. 4.

Beside bands from skin components (protein $\mathrm{C}=\mathrm{O}$ at $1649 \mathrm{~cm}^{-1}$ ) and inorganic contaminants (probably silicate at 1011 $\mathrm{cm}^{-1}$ ) the spectrum shows bands at 2920, 2850, 1465 and $720 \mathrm{~cm}^{-1}$, which can be assigned to $\mathrm{CH}$ vibrations of fatty alkyl chains. Furthermore two bands at 1579 and $1539 \mathrm{~cm}^{-1}$ assignable to ionic carboxylate groups suggest that salts of fatty acids must be present. In some spectra (not shown here) bands at about 1740 (ester $\mathrm{C}=\mathrm{O}$ stretch) and $1710 \mathrm{~cm}^{-1}$ (acid $\mathrm{C}=\mathrm{O}$ stretch) indicating the presence of fatty esters (triglycerides) and fatty acids could also be detected, but they are generally weaker than the bands at 1579 and $1539 \mathrm{~cm}^{-1}$, indicating that fatty acids are predominantly present in a salt form.

It is also worth noting that in two of the four pieces of leather analysed much more protein could be found on the hair

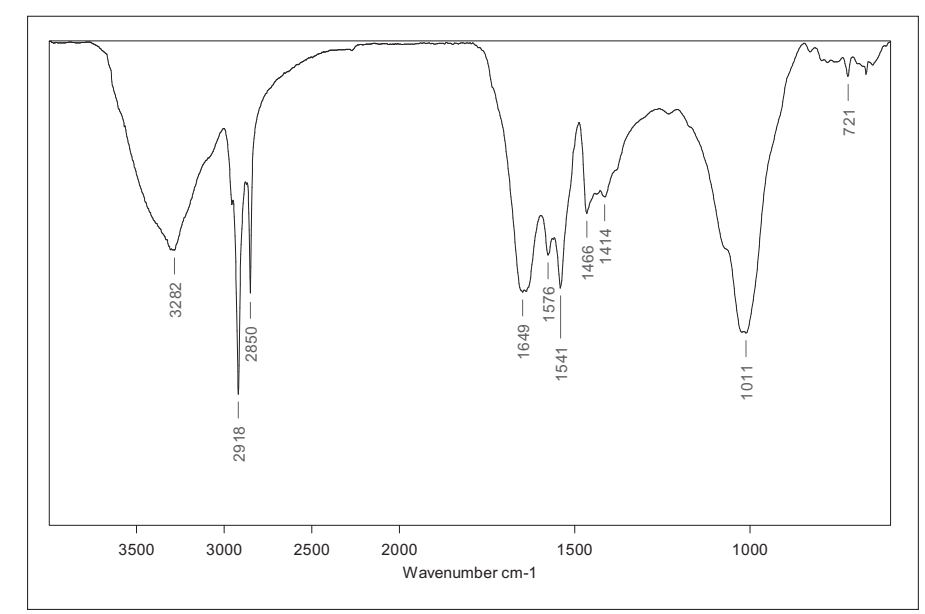

Fig. 4. ATR spectrum of the flesh side of a sample of Ötzi's trousers. 


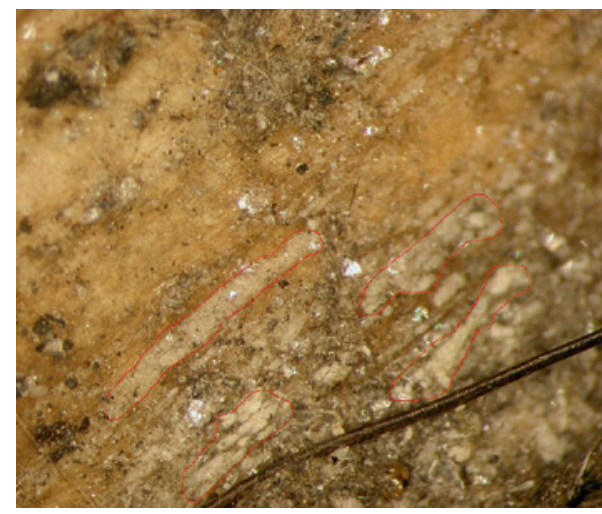

Fig. 5. Light microscope image of fatty spew on the Ötzi leather (20x magnification).

side than on the flesh side, whereas in the other two samples both sides could not be clearly distinguished by their ATR spectra.

Since some fatty spew could be observed on one of Ötzi's leather samples under the light microscope (Fig. 5), some particles were removed with a metallic needle and then analyzed with the Fourier transform infrared spectroscopy (FTIR) microscope in transmission mode. Although the IR spectra (Fig. 6) differ slightly from particle to particle, they confirm that the main fatty component found on Ötzi's leather is clearly a salt of a saturated fatty acid, most likely a calcium salt of stearic acid or of a close homologue. Only a small concentration of free acid is present (1699 $\mathrm{cm}^{-1}$ ). This result was confirmed by comparing the spectrum of the fatty particles with the spectrum of pure commercial calcium stearate (Fig. 7), which exhibits the same typical split carboxylate band which is converted to one single band when the sample is dried. ${ }^{[13]}$ The absence of significant amounts of inorganic carbonate in the IR spectra almost rules out that the calcium found on Ötzi's leather by atom absorption spectroscopy (see Table 1) could originate from dolomite contamination.

Table 2. Results of the IR investigation on natural fat or fat derivatives.

$\begin{array}{lll}\text { Age } & \text { Type } & \text { Fat content } \\ \text { 11th century } & \text { Upper footwear, vegetable } & \text { low } \\ \text { 12th century } & \text { Upper footwear, vegetable } & \text { low } \\ \text { 14th century } & \text { Sole leather vegetable } & \text { almost none } \\ \text { New, classical standard } & \text { Glace gloving, alum } & \text { low } \\ \text { New, classical standard } & \text { German deer, chamois } & \text { medium } \\ \text { New, rediscovered } & \text { Indian, elk, smoked } & \text { high (mainly fatty esters) } \\ \text { New, rediscovered } & \text { Siberian, fish } & \text { high } \\ \text { 4th millennium BC (Copper age) } & \text { Iceman fur } & \text { high (mainly fatty acid salts) }\end{array}$

We tried to confirm our findings by analysing the fatty particles with other analytical methods which was not easy due to the very low solubility of the sample and also to the small amount of material. Some indication could be obtained from mass spectrometry (ESI-MS) showing the presence of palmitic acid, stearic acid and hydroxystearic acid after strong acidification of a fatty particle. However, MS did not bring any information about the concentration of the detected species since only a very small part of the particle could be solubilised even after treatment with acid.

Another clue was provided by an energy dispersive X-ray (EDX) analysis, which revealed that calcium was the main element in a fatty particle beside smaller concentrations of aluminium, silicon and sodium. ${ }^{[14]}$

Surprisingly, the expected natural fatty esters and free fatty acids were only present as minor components. Also, unsaturated fat components or an indication that saturated fat had been oxidized was not clearly found. Their absence exclude that the fur had been impregnated with fish oil. Based on these results we concentrated our further analytical efforts on fat tanning approaches of various kinds and fat-containing leather in general. We especially focused on various types of historical leather treatments, excluding metal and vegetable additions, in order to assess which type of procedure was used by the Iceman.

To obtain reference data we investigated leather from the 11 th, 12 th, and 14 th centuries as well as different types of vegetable, chamois (fat) and glace (aluminium) leather. ${ }^{[15]}$ As an additional reference we looked into newly rediscovered techniques from ancient US/Canada Indian ${ }^{[16]}$ and Siberian leather ${ }^{[17]}$ handicraft. Supplementary analytical methods were used, such as X-ray fluorescence, to cross-check and verify the original findings or to exclude other possibilities. Table 2 summarises the analytical results in terms of fat amount and nature as determined in the various leather sample types.

The Iceman's fur proved to be very different from the reference leather samples. Fat was found but a strikingly high concentration of calcium salts of saturated fatty acids distinctly characterised the Iceman's leather sample.

We concluded that a unique, rather unexpected lubrication procedure could have

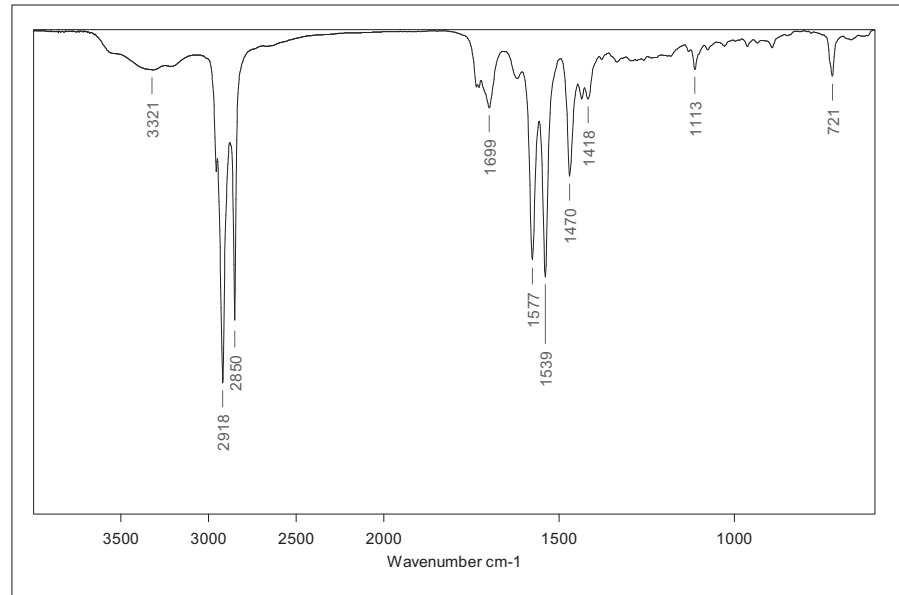

Fig. 6. IR microscope spectrum of a typical fatty particle from Ötzi's leather.

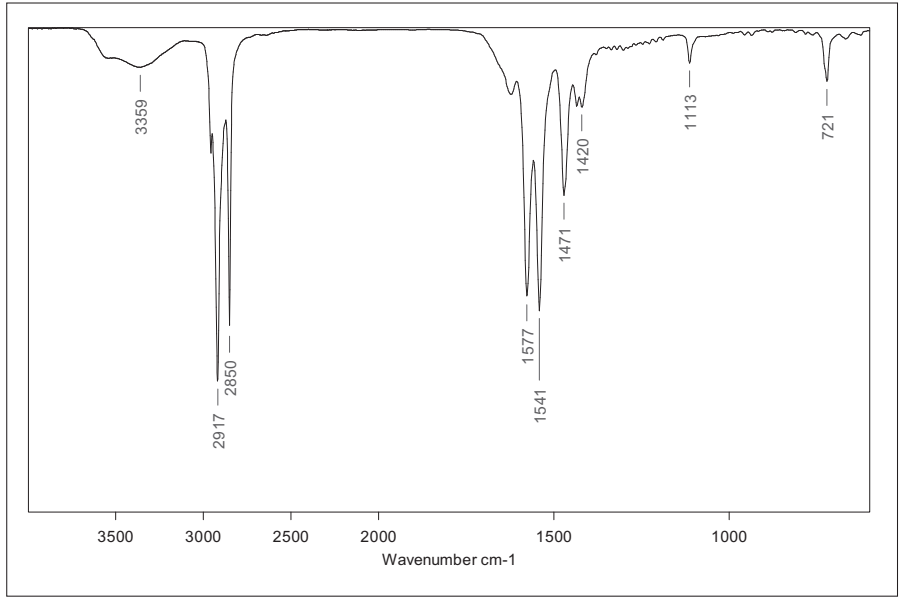

Fig. 7. IR microscope spectrum of calcium stearate. 
been used. The IR spectra are different from those obtained from leathers treated by modern fat liquoring methods as well as completely different from the more ancient chamois tanning type applied to Tyrolean trousers (Fig. 8). On the Tyrolean trousers there is a much lower concentration of fatty components compared to Ötzi's clothes.

At this stage of our investigation some questions still needed to be answered: "What is the origin of the salts of fatty acids found on the Ötzi's clothes? Was an unknown tanning method used in the Alps in this epoch?"

\section{Further Investigation of Possible Old Tanning Methods}

It is well known that long chain fatty acids can be produced from natural triglycerides by microbial activity typically found in soil. As an example, body fat is decomposed to adipocere by bacterial enzymes that cleave the fatty acids from the glycerol molecule. In soils the cleaved fatty acids may be easily converted to their calcium salts. ${ }^{[12,18]}$ Therefore, one could envisage that Ötzi's clothes could have been immersed deliberately in soil after impregnation with fat or that fat simply decomposed slowly in the glacier flow over this long period of time.

These hypotheses did not satisfy us entirely and we therefore tried to imagine a possible alternative tanning technique, which, although no documentary evidence existed, could have been used in those times, to explain the presence of the high concentration of calcium salts of saturated fatty acids.

Calcium stearate and its homologues are known as water repellents, even stronger than fat alone. In today's tanning process lime soap is known to be poorly soluble and results in smudges and stains.
However, our ancestors may have emphasized more the practical waterproof effect rather than the leather's appearance. We hypothesised that already in those ancient times an intelligent and resourceful individual could have discovered that animal fat could be saponified with wood ash and we developed a procedure based on upon this idea.

Ash obtained by complete incineration of wood is mainly composed of oxides and has a $\mathrm{pH}$ of $10 \sim 13$. The ash composition of deciduous trees contains approx. 3-4\% potassium, $15.3-46 \%$ calcium, $1-2 \%$ magnesium and 1-2\% phosphorus. [19]

We cooked fat with ash in water under constant stirring and we obtained a fine emulsion ${ }^{[20]}$ after removing the ash residue. Such a mixture consists of soluble alkaline fat and dispersed alkaline earth fats, as well as emulsified unsaponified starting materials (Fig. 9). The untreated fat releases free fatty acids upon ageing, typically leading to fatty spew, which should be avoided in modern tanning techniques but which was surely not a problem in ancient times.

In this process, the possibility of side reactions with unsaturated fat can be discarded as the amounts of these by-products are too small in animal fat. Therefore, the principle of this tanning method is the production of high quantities of calcium salts of saturated fatty acids from land animal fat by control of time, temperature and other reaction conditions. With this mixture we were able to obtain similar tanning effects as on Ötzi's fur. The emulsion as such could be much more easily incorporated into the hide than untreated fat. ${ }^{[21]} \mathrm{We}$ did this either by immersion in a bath or mechanically with stuffing auxiliaries such as the remaining ash or with other supporting materials and we had to carefully monitor the $\mathrm{pH}$ because high $\mathrm{pH}$ destroys the hair and the skin. We however did not find any suitable organic carrier or any organic emulsifier on the Ötzi's fur, but we cannot exclude the presence of colloidal clay.

\section{Conclusion}

In the course of investigating the tanning method used for the leather clothes of Ötzi, a surprisingly high concentration of calcium salts of saturated fatty acids was found on the surface of the leather clothes. As this finding cannot be explained by today's tanning methods, we concluded that a unique tanning procedure could have been used.

We developed a tanning method which could have been employed in this early time. This method was applied to leather to obtain accurate reference data. The analytical results from the reference fur sample were in good agreement with those obtained from Ötzi's clothes. This allows us to conclude that tanning of the Iceman's clothes partly consisted of saponified land animal fats, which had been physically incorporated, mainly in the form of calcium stearate. The superior water-repellent effect of this tanning procedure would have been especially suitable for the rainy, snowy and generally wet alpine conditions of the region inhabited by Ötzi. This may have been the beginning of the water-repellent treatment of leather and fur.

\section{Acknowledgements}

At the end of 1992 we received first information of the Iceman leather findings and a request for analytical help. At that time we were Ciba-Geigy AG employees. We obtained very small pieces of Ötzi's leather clothes from Dipl. Ing. J. Lange $\dagger$ for analytical investigation; the work basically represented our 'leisure time research', which involved a lot of other researchers, and survived many personal changes (retirement and re-location) and company developments (mergers and

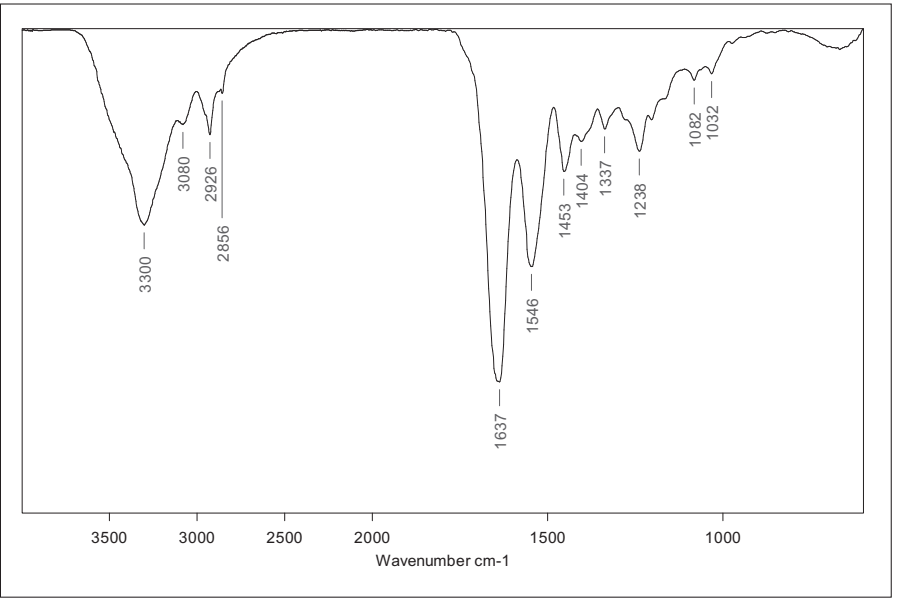

Fig. 8. ATR spectrum of Tyrolean trousers.

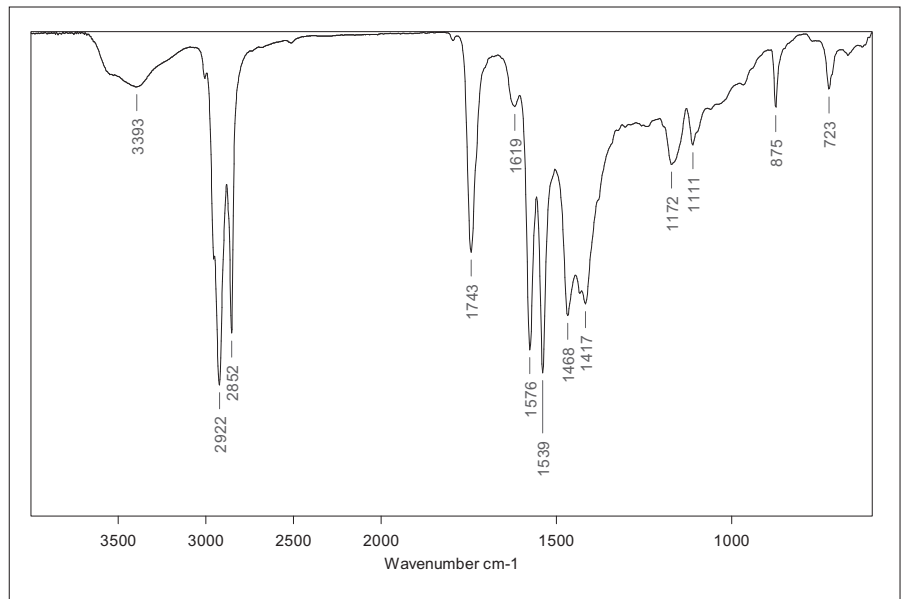

Fig. 9. IR spectrum of a fat saponified with wood ash. 
spin-offs). We conclude our work with this final report and update earlier presentations given at the XXVIII IULTCS CONGRESS, March 9-12, 2005 in Florence, Italy and 59 annual meeting of VGCT, Mai 10-11, 2007 in Bad Reichenhall, Germany. Last but not least we would like to say thank-you to all the supporters, researchers, our supervisors and our companies for allowing us to use their equipment. We thank also U. Bergamin and P. Acker for their technical assistance in IR work, C. Guenat for MS measurements, K. Pulver for EDX analysis, J. Pavel and D. Heim for elemental analysis and $\mathrm{H}$. Schroeder and R. Falchetto for reviewing the manuscript. Finally, we hope that in the future others will confirm or modify our assumption of early leather production with a 1:1 field trial.

Received: March 30, 2010

[1] Recommended Website: http://www.iceman.it

[2] M. Egg, K. Spindler, W. Groeman-van Waateringe, 'Die Gletschermumie vom Ende der Steinzeit', Jahrbuch des RömischGermanischen Zentralmuseums Mainz 1992, 39, Teil 1,1.

[3] K. Spindler, 'The Man in the Ice', Weidenfeld \& Nicolson, London, 1994.

[4] F. Hopfel, W. Platzer, K. Spindler, 'Der Mann im Eis', Bericht über das Internationale Symposium 1992 in Innsbruck, Eigenverlag der Universität Innsbruck, 1992.

[5] K. Hollemeyer, W. Altmeyer, E. Heinzle, C. Pitra, Rapid Commun. Mass Spectrom. 2008, 22, 2751.

[6] T. Körner, 'Geschichte der Gerberei', in 'Handbuch der Gerbereichemie', Springerverlag, Wien, 1944, p 1.
[7] B. Tommer, 'Die Kollagenmatrix archäologischer Funde im Vergleich zu künstlich gealterten Ledermustern historischer Gerbverfahren', Dissertation an der Technischen Universität Bergakademie Freiberg, 2005.

[8] J. Dewhurst, J. Soc. Leather Technol. Chem. 2004, 88,260 .

[9] A. Gansser, 'Die Vor- und Frühzeit der Gerberei', CIBA-Rundschau 1949, 85, 3156.

[10] Private communication from J. Lange†, LGR Reutlingen, Germany.

[11] L. Küpper, H. M. Heise, F.-G. Bechara, M. Stücker, J. Mol. Struct. 2001, 565-566, 497.

[12] T. Bereuter, C. Reiter, W. Mikenda, Chem. Brit. 1999, 25.

[13] J. Bagg, M. B. Abramson, M. Fichman, M. D. Haber, H. P. Gregor, J. Am. Chem. Soc. 1964, 86, 2759.

[14] Private communication, K. Pulver, Solvias, Basel.

[15] Private collection, J. Lange, LGR Reutlingen.

[16] Private communication, N. Robert, Fort St. James, National Historic Park, Canada.

[17] Private communication, A. Dokan, Nanai tanner, Vietach, Germany.

[18] S. L. Forbes, B. H. Stuart, I. R. Dadour, B. B. Dent, J. Forensic Sci. 2004, 49, 566.

[19] A. Zoller, N. Remler, H.-P. Dietrich, 'Eigenschaften von Holzasche und Möglichkeiten der Wiederverwertung im Wald', Landesanstalt für Wald und Forstwirtschaft, LWF Bericht 14, 1997.

[20] Small laboratory test, R. Saumweber, Basel.

[21] Small field test, G. Renner, Basel. 